Article

\title{
High-Performance SiC-Polycrystalline Fiber with Smooth Surface
}

\author{
Ryutaro Usukawa and Toshihiro Ishikawa * \\ Department of Applied Chemistry, Tokyo University of Science, Yamaguchi, 756-0884 Yamaguchi, Japan; \\ F118701@ed.tusy.ac.jp \\ * Correspondence: ishikawa@rs.tusy.ac.jp; Tel.: +81-836-88-4564
}

Received: 28 June 2018; Accepted: 22 August 2018; Published: 23 August 2018

\begin{abstract}
Polymer-derived SiC-polycrystalline fibers show excellent heat-resistance up to $2000{ }^{\circ} \mathrm{C}$, and relatively high strength. Up to now, through our research, the relationship between the strength and residual defects of the fiber, which were formed during the production processes (degradation and sintering), has been clarified. In this paper, we addressed the relationship between the production conditions and the surface smoothness of the obtained SiC-polycrystalline fiber, using three different raw fibers (Elementary ratio: $\mathrm{Si}_{1} \mathrm{Al}_{0.01} \mathrm{C}_{1.5} \mathrm{O}_{0.4 \sim 0.5}$ ) and three different types of reactors. With increase in the oxygen content in the raw fiber, the degradation during the production process easily proceeded. In this case, the degradation reactions $\left(\mathrm{SiO}+2 \mathrm{C}=\mathrm{SiC}+\mathrm{CO}\right.$ and $\left.\mathrm{SiO}_{2}+3 \mathrm{C}=\mathrm{SiC}+2 \mathrm{CO}\right)$ in the inside of each filament become faster, and then the $\mathrm{CO}$ partial pressure on the surface of each filament was considered to be increased. As a result, according to Le Chatelier's principle, the surface degradation reaction and grain growth of formed $\mathrm{SiC}$ crystals would be considered to become slower. That is to say, using the raw fiber with higher oxygen content and closed system (highest CO content in the reactor), a much smoother surface of the SiC-polycrystalline fiber could be achieved. Furthermore, the similar effect obtained by simple oxidation of the SiC-polycrystalline fiber was confirmed, and the advantageous points of the aforementioned process were also considered.
\end{abstract}

Keywords: SiC-polycrystalline fiber; Defect; Strength; Surface roughness

\section{Introduction}

Since the first precursor ceramics using polycarbosilane were developed [1], many polymer-derived SiC-base fibers have been developed [2-6]. Present commercial polymer-derived $\mathrm{SiC}$ fibers are shown in Table 1. Through these developments, the heat-resistances of the SiC-based fibers were remarkably increased from $1300{ }^{\circ} \mathrm{C}$ to $2000{ }^{\circ} \mathrm{C}$, as can be seen from this table. Of these fibers, $\mathrm{SiC}$-polycrystalline fibers (Tyranno SA, Hi-Nicalon Type S, and Sylramic) show the highest heat-resistance up to $2000^{\circ} \mathrm{C}$, and then have been actively evaluated for aerospace applications as $\mathrm{SiC} / \mathrm{SiC}$ composites [7-11]. However, to extend the application field, increases in the fiber's strength is eagerly required. Up to now, through our research, the relationship between the strength and the residual defects contained in the fiber, which were formed during the production processes, have been clarified [12-15]. In these studies, we have proposed several new methods for reducing the residual defects, and also demonstrated them using the conversion process, from amorphous Si-Al-C-O fiber to SiC-polycrystalline fiber (Tyranno SA). Tyranno SA is produced by heat-treatment processes of amorphous Si-Al-C-O fiber which is synthesized from polyaluminocarbosilane [5]. During the heat-treatment processes, a degradation of the Si-Al-C-O fiber and a subsequent sintering of the degraded fiber proceed as well, accompanied by a release of $\mathrm{CO}$ gas and compositional changes, to finally obtain the dense structure. Since these structural changes proceed in each filament, strict 
control is needed to minimize residual defects. As mentioned above, to reduce the residual defects, we have proposed new conversion processes and demonstrated them in our previous reports [13-15].

Table 1. Commercial Polymer-derived SiC Fibers [2].

\begin{tabular}{|c|c|c|c|c|}
\hline Classification (Development) & Heat-Resistant Temperature & Grade Name & Manufacturer & Phase \\
\hline First generation $(\sim 1990)$ & $\sim 1300{ }^{\circ} \mathrm{C}$ & $\begin{array}{c}\text { Nicalon NL } 200 \\
\text { Tyranno Lox M } \\
\text { Tyranno S }\end{array}$ & $\begin{array}{l}\text { NGS } \\
\text { UBE } \\
\text { UBE }\end{array}$ & Amorphous \\
\hline Second generation $(\sim 1996)$ & $\sim 1500{ }^{\circ} \mathrm{C}$ & $\begin{array}{l}\text { Hi-Nicalon } \\
\text { Tyranno ZMI }\end{array}$ & $\begin{array}{l}\text { NGS } \\
\text { UBE }\end{array}$ & Amorphous \\
\hline Third generation $(\sim 1998)$ & $\sim 2000{ }^{\circ} \mathrm{C}$ & $\begin{array}{c}\text { Hi-Nicalon Type S } \\
\text { Tyranno SA } \\
\text { Sylramic }\end{array}$ & $\begin{array}{c}\text { NGS } \\
\text { UBE } \\
\text { COIC }\end{array}$ & $\beta$-SiC Crystal \\
\hline
\end{tabular}

A remarkable decrease in the number of inside defects was noticed after applying the aforementioned new processes. As the result of this research, the present maximum strength of the improved fiber is $\sim 4 \mathrm{GPa}$. However, this strength is remarkably low compared to the theoretical strength (46 GPa) of SiC crystal, which can be calculated using Orowan's equation [16]. Accordingly, further improvement is needed. In the above research, by controlling the advantageous degradation-reaction and preventing the disappearance of gaseous $\mathrm{SiO}$ from each filament, residual carbon (one of the residual defects) was remarkably reduced along with prevention of abnormal surface grain growth. As a result, the surface smoothness observed by FE-SEM was relatively improved compared with that of previous fibers. Furthermore, surface smoothness was very sensitive depending on the atmospheric condition during the degradation process, and so obtaining a much smoother surface was a relatively difficult problem. Smoother surface of the fiber is very important for obtaining good fibrous fracture behavior of ceramic matrix composites (CMCs) [17]. Therefore, it is important to clarify the relationship between the process condition and the surface smoothness of the obtained fiber. From these points, in this study, we describe the formation mechanism of the surface structure and the relationship between the process condition and the surface smoothness of the obtained $\mathrm{SiC}$-polycrystalline fiber. Furthermore, we touched on the other method (simple oxidation of the SiC-polycrystalline fiber) to obtain the smooth surface.

\section{Materials and Methods}

The raw fiber (Si-Al-C-O fiber) was synthesized in accord with the previous paper [5]. To study the differences in the surface smoothness after heat-treatment (degradation and sintering) of Si-Al-C-O fiber, three different types of raw fibers, which were prepared by changing the curing temperatures $\left(180-200^{\circ} \mathrm{C}\right)$, were used. The elemental ratios of the raw fibers were $\mathrm{Si}_{1} \mathrm{Al}_{0.01} \mathrm{C}_{1.5} \mathrm{O}_{0.4}, \mathrm{Si}_{1} \mathrm{Al}_{0.01} \mathrm{C}_{1.5} \mathrm{O}_{0.45}, \mathrm{Si}_{1} \mathrm{Al}_{0.01} \mathrm{C}_{1.5} \mathrm{O}_{0.5}$.

As mentioned in our previous report [12], the surface smoothness of the obtained $\mathrm{SiC}$-polycrystalline fiber depends on the atmospheric conditions during the heat-treatment process. Specifically, the concentration of carbon monoxide gas (hereafter CO gas) in the reactor strongly affected the surface smoothness [12].

In this study, two methods were performed to obtain the smooth surface. The first method is a simple oxidation $\left(1300{ }^{\circ} \mathrm{C}, 30 \mathrm{~min}\right)$ of the obtained $\mathrm{SiC}$-polycrystalline fiber; subsequent hydrofluoric acid treatment (10\% aqueous solution, 3 hours) results in the modified surface.

The second method is to directly change the $\mathrm{CO}$ gas content in the reactor during the heat-treatment process. To experimentally achieve this object, we adopted the aforementioned three different types of raw fibers, and three different types of carbon vessels. In this case, we used carbon vessel whose inner-diameter and height were $10 \mathrm{~mm}$ and $50 \mathrm{~mm}$, respectively. Only one was a carbon vessel with three through holes of $3 \mathrm{~mm}$ diameter. The aforementioned three different types of carbon vessels are as follows. 
(1) The abovementioned carbon vessel without cover (hereafter "open system")

(2) The carbon vessel with the abovementioned three through holes and cover (hereafter "partially-open system")

(3) The abovementioned carbon vessel with cover (hereafter "closed system")

For heat-treatment (degradation reactions and sintering) of the Si-Al-C-O fiber, we applied "Super High Temperature Inert Gas Furnace (NEWTONIAN Pascal-40, Produced by NAGANO)" under argon gas flow $(1 \mathrm{~L} / \mathrm{min})$. The size of the heating zone (made of graphite and $\mathrm{C} / \mathrm{C}$ composites) is $35 \mathrm{~mm}$ in diameter and $40 \mathrm{~mm}$ in height. Several types of raw fibers (about $10 \mathrm{mg}$ ) (Elementary ratio: $\mathrm{Si}_{1} \mathrm{Al}_{0.01} \mathrm{C}_{1.5} \mathrm{O}_{0.4 \sim 0.5}$ ) were used and located in each vessel. The heating rate and the maximum temperature were $400 \mathrm{~K} / \mathrm{min}$ and $1900{ }^{\circ} \mathrm{C}$, respectively. The applied experimental conditions are shown in Figure 1.

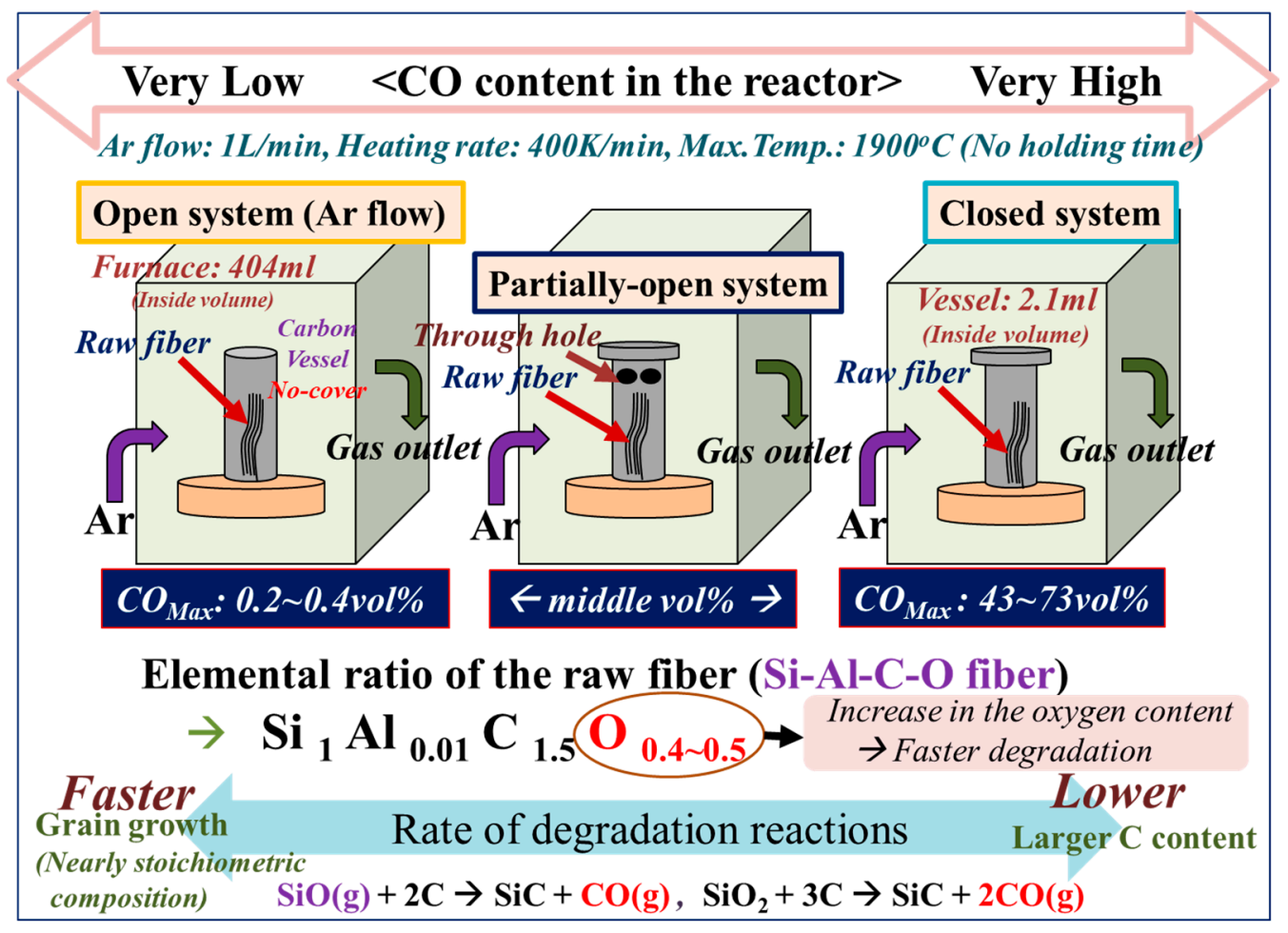

Figure 1. Applied experimental conditions to study the fiber's surface smoothness.

The surfaces and cross sections of the obtained fibers were observed using a field emission scanning electron microscope (FE-SEM), model JSM-700F (JEOL, Ltd., Tokyo, Japan). EBSD (Electron Back Scatter Diffraction) mapping was measured using the same FE-SEM. Surface roughness was observed using Atomic Force Microscope (AFM), model AFM 5000II (Hitachi, Ltd., Tokyo, Japan).

\section{Results and Discussion}

\subsection{Modification of the Surface Smoothness by Simple Oxidastion of the SiC-Polycrystalline Fiber}

In this study, commercial Tyranno-SA (produced by Ube Industries, Ltd., Yamaguchi, Japan) was used as the starting material. Using an atmospheric furnace, Tyranno-SA was oxidized at $1300^{\circ} \mathrm{C}$ for $30 \mathrm{~min}$. After that, the oxidized fiber was immersed in 10\% aqueous solution of hydrofluoric acid for 3 hours. For a comparison, untreated Tyranno-SA was also treated by the same $10 \%$ aqueous solution of hydrofluoric acid. The polished cross-sections (FE-SEM images) of the surface regions of the treated fibers are shown in Figure 2. As can be seen from this figure, the surface smoothness was improved, however the effect was relatively small. Furthermore, since this type of fiber is used as a 
high-temperature structural material, surface oxide-layer has to be removed as this study. So, this method is not found to be useful.

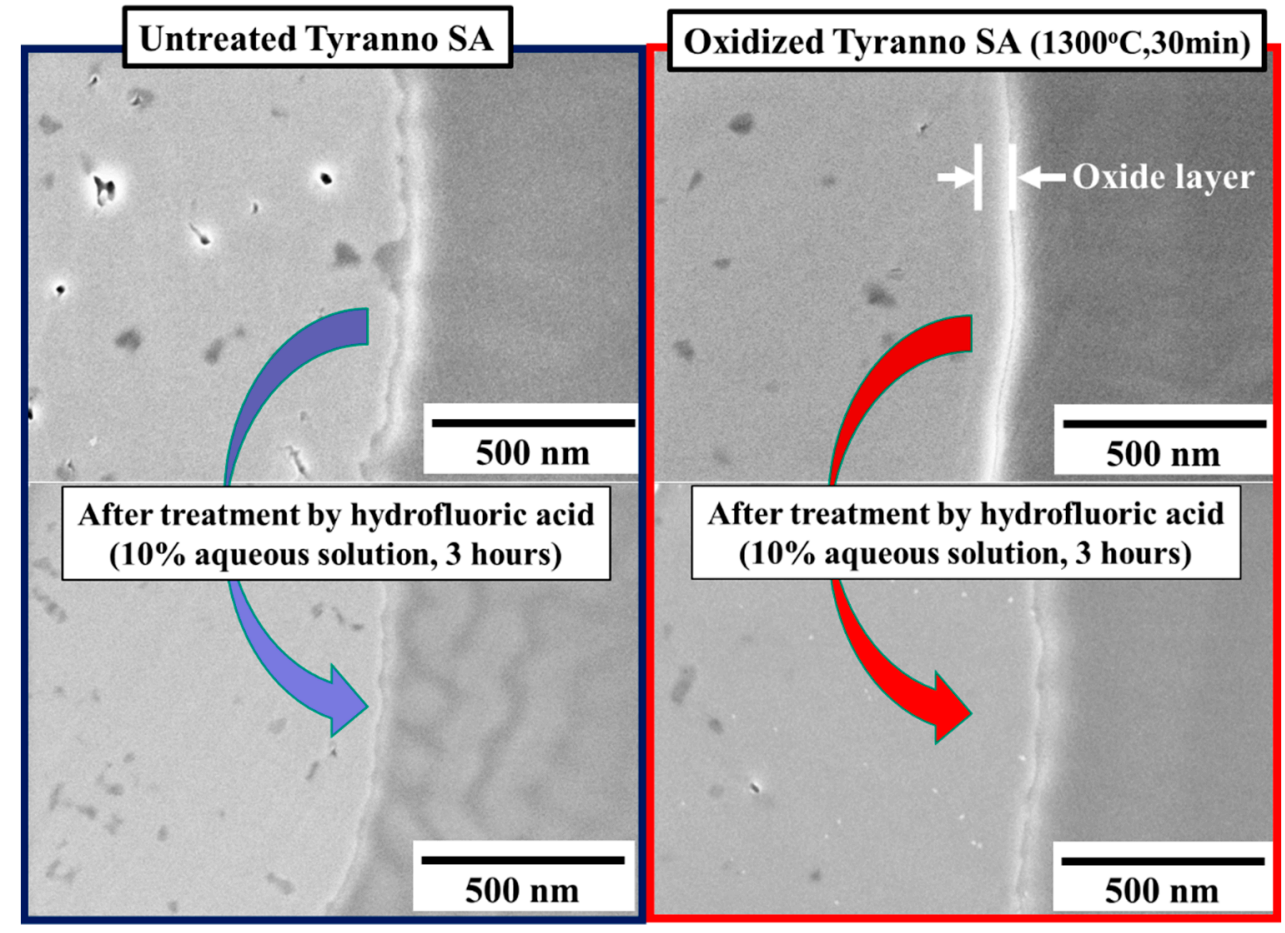

Figure 2. Changes in the surface smoothness by simple oxidation $\left(1300{ }^{\circ} \mathrm{C}, 30 \mathrm{~min}\right)$ and hydrofluoric acid treatment (10\% aqueous solution, 3 hours).

\subsection{Changes in the Fine Composition during the Degradation Process}

In order to obtain the $\mathrm{SiC}$-polycrystalline fiber, at the first step, the amorphous $\mathrm{Si}$-Al-C-O fiber was heat-treated up to $1500{ }^{\circ} \mathrm{C}$ in argon gas atmosphere. During the heat-treatment process, by the existence of the oxide phase and excess carbon in the fiber, the amorphous Si-Al-C-O fiber was degraded accompanied by a release of $\mathrm{CO}$ gas to obtain a porous degraded fiber. It was published in our previous paper $[5,7,13]$ that this degradation of the Si-Al-C-O fiber proceeds mainly by the following two types of reactions.

$$
\begin{gathered}
\mathrm{SiO}_{2}+3 \mathrm{C}=\mathrm{SiC}+2 \mathrm{CO}\left(\triangle \mathrm{G}<0 \text { over } 1522^{\circ} \mathrm{C}\right) \\
\mathrm{SiO}+2 \mathrm{C}=\mathrm{SiC}+\mathrm{CO}(\triangle \mathrm{G}<0 \text { at all temperatures range })
\end{gathered}
$$

The porous degraded fiber was composed of a nearly stoichiometric SiC composition containing small amount of aluminum (less than $1 \mathrm{wt} \%$ ). By the existence of the small amount of aluminum, in the next step, an effective sintering proceeded in each degraded filament composed of the nearly stoichiometric $\mathrm{SiC}$ crystals during further heat-treatment up to $1900{ }^{\circ} \mathrm{C}$ in $\mathrm{Ar}$ gas atmosphere [5]. And then, the dense SiC-polycrystalline fiber was obtained.

As mentioned in our previous paper [14], the degradation proceeded from outside to inside of the amorphous $\mathrm{Si}-\mathrm{Al}-\mathrm{C}-\mathrm{O}$ fiber. As mentioned before, the degradation reactions $\left(\mathrm{SiO}_{2}+3 \mathrm{C}=\mathrm{SiC}+2 \mathrm{CO}\right.$ and $\mathrm{SiO}+2 \mathrm{C}=\mathrm{SiC}+\mathrm{CO}$ ) are strongly dominated by the $\mathrm{CO}$ gas content in the reactor. According to Le Chatelier's principle, the higher the $\mathrm{CO}$ content becomes, the slower the reaction becomes. Anyway, the abovementioned degradation proceeds in the inside of each filament accompanied by a release of $\mathrm{CO}$ gas. So, the inside of each filament is saturated by the formed $\mathrm{CO}$ gas, and the surplus $\mathrm{CO}$ gas must be ejected from the surface region to the outside. Furthermore, on the surface 
region of each filament, some boundary layer composed of $\mathrm{CO}$ gas is estimated to be formed. By these changes, in consequence, some $\mathrm{CO}$ gas distribution would be formed from the inside the surface region of each filament. Accordingly, the degradation in the inside of each Si-Al-C-O filament was considered to proceed as shown in Figure 3.

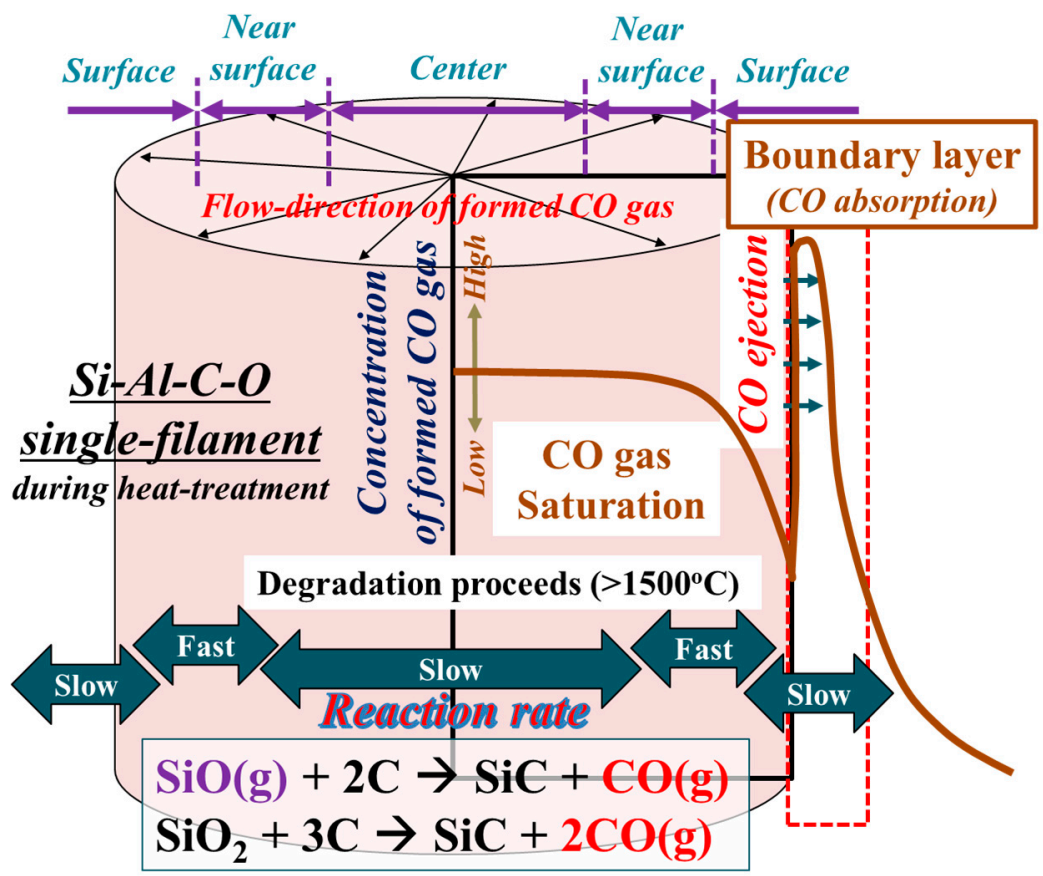

Figure 3. Estimated degradation-process in the inside of each Si-Al-C-O filament.

This figure shows the estimated degradation reaction inside the raw Si-Al-C-O filament. As mentioned above, according to Le Chatelier's principle, these reaction-rates are dominated by the partial pressure of the formed $\mathrm{CO}$ gas. When these reactions proceed in each filament, the inside of each filament is saturated by the formed $\mathrm{CO}$ gas. However, from the surface region, the formed $\mathrm{CO}$ gas is estimated to be ejected. Accordingly, the $\mathrm{CO}$ gas partial pressure of the near-surface region would become lower compared with that of the inside. So, the reaction rate would become lower at the center of each filament, compared with that of the near surface region. On the other hand, on the surface of the raw fiber, a boundary layer composed of $\mathrm{CO}$ gas is estimated to be formed. In consequence, at the surface, $\mathrm{CO}$ gas concentration would become relatively higher compared with that of the inside. These CO gas-balance is considered to dominate the fine structures of the obtained SiC-polycrystalline fiber. Regarding the above phenomena, the EBSD (Electron Back Scatter Diffraction) mapping of the polished cross-section of the obtained SiC-polycrystalline fiber is shown in Figure 4. As can be seen from this figure, the grain size at each position was different from each other. As mentioned above, the degradation rate and the obtained grain-size are considered to be dominated by the partial pressure of the formed $\mathrm{CO}$ gas. $\mathrm{CO}$ gas concentration of the near-surface region of the fiber is estimated to be relatively low compared with that of the inside, so that the reaction rate would become higher to lead to larger grain size compared with that of the inside. Furthermore, since the boundary layer composed of the ejected CO gas was considered to be formed on the surface, the partial pressure of $\mathrm{CO}$ gas on the surface would become higher to result in the smaller grain size. Considering these fundamental matters, we can control the surface smoothness. In the next section, we will address the relationship between the degradation reaction at the surface and the surface smoothness of the obtained SiC-polycrystalline fiber. 


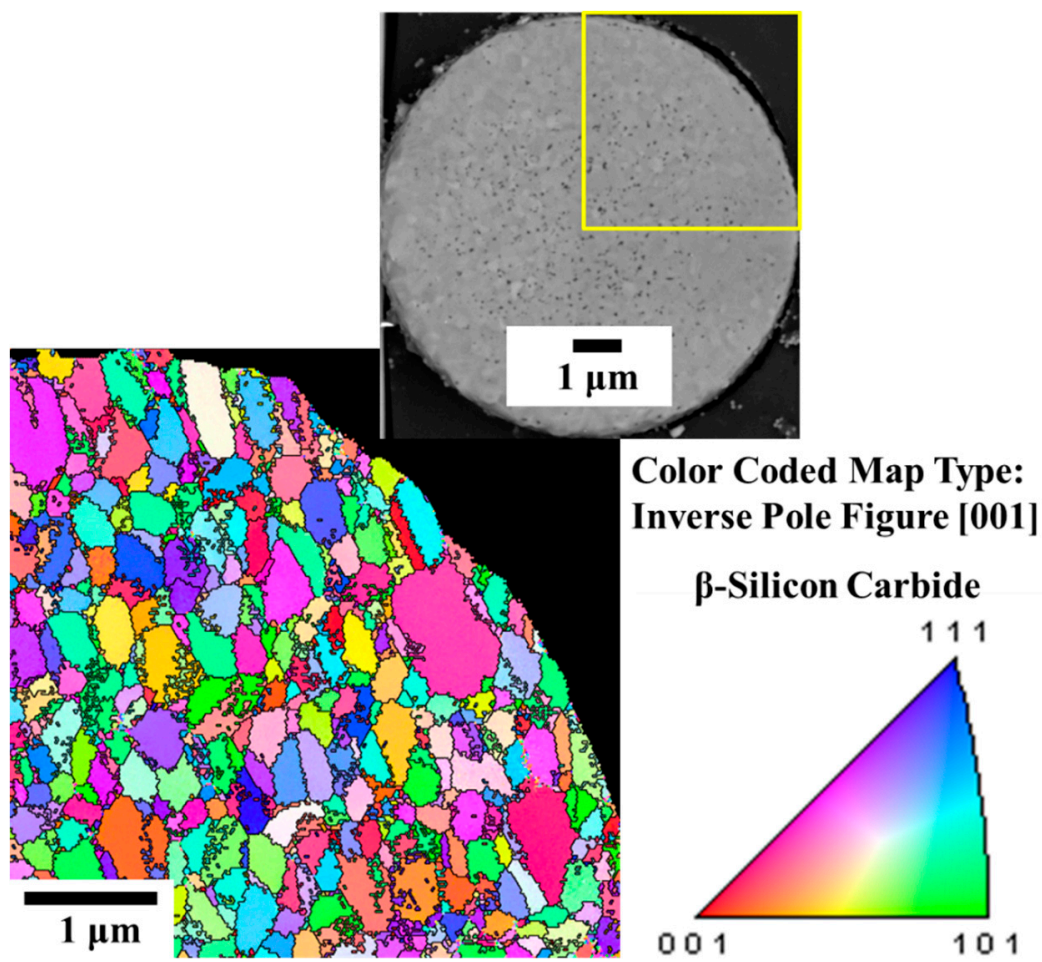

Figure 4. Electron Back Scatter Diffraction (EBSD) mapping of the polished cross-section of the obtained SiC-polycrystalline fiber.

\subsection{Change in the Surface Smoothness of the SiC-Polycrystalline Fiber}

Both the degradation reaction and the grain growth of the formed $\mathrm{SiC}$ crystals are strongly affected by the $\mathrm{CO}$ gas content in the reactor during the degradation reaction. Regarding this, in the industrial production process, $\mathrm{CO}$ gas concentration in the continuous furnace can be controlled by controlling the argon gas flow. Accordingly, the results of our approach are applicable to the industrial production process.

As shown in Figure 1, we used three different types of vessel (Open system, Partially-open system, and Closed system) and three different types of raw fiber (Elementary ratio: $\mathrm{Si}_{1} \mathrm{Al}_{0.01} \mathrm{C}_{1.5} \mathrm{O}_{0.4 \sim 0.5}$ ) for changing actual $\mathrm{CO}$ content in the reactor. Under the applied reaction condition, the maximum $\mathrm{CO}$ content in the reactor was $73 \mathrm{vol} \%$ when used both the closed system and the raw fiber with highest oxygen content $\left(\mathrm{Si}_{1} \mathrm{Al}_{0.01} \mathrm{C}_{1.5} \mathrm{O}_{0.5}\right)$, whereas the minimum $\mathrm{CO}$ content was $0.2 \mathrm{vol} \%$ when used both the open system and the other raw fiber with lowest oxygen content $\left(\mathrm{Si}_{1} \mathrm{Al}_{0.01} \mathrm{C}_{1.5} \mathrm{O}_{0.4}\right)$. The surface structures (FE-SEM images) of the obtained SiC-polycrystalline fibers are shown in Figure 5. 


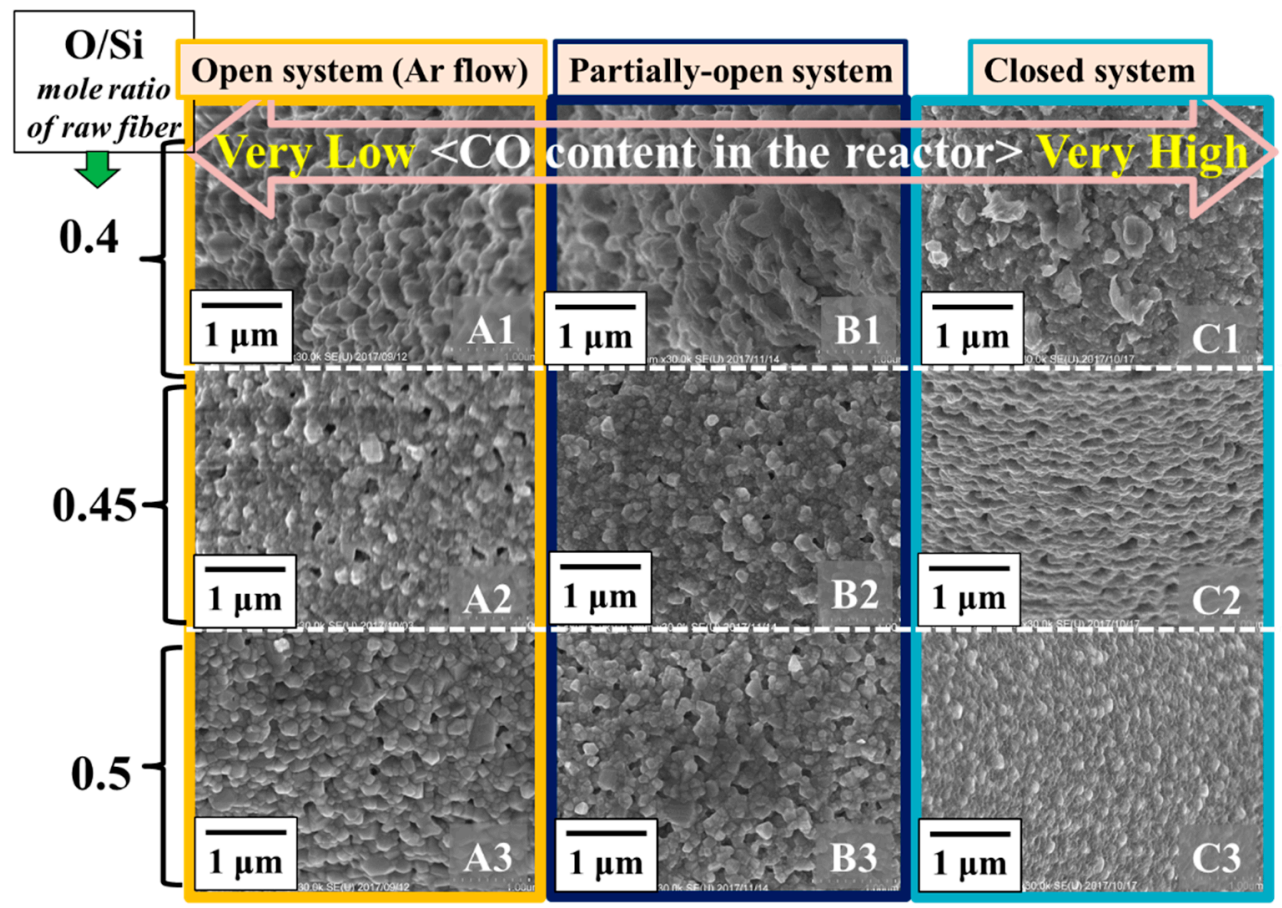

Figure 5. Changes in the surface structures obtained using different types of raw fiber and vessels. For obtaining $\mathrm{A} 1, \mathrm{~B} 1, \mathrm{C} 1$, the raw fiber composed of $\mathrm{Si}_{1} \mathrm{Al}_{0.01} \mathrm{C}_{1.5} \mathrm{O}_{0.4}$ was used. For obtaining $\mathrm{A} 2, \mathrm{~B} 2$, $\mathrm{C} 2$ and for obtaining $\mathrm{A} 3, \mathrm{~B} 3, \mathrm{C} 3$, the raw fibers composed of $\mathrm{Si}_{1} \mathrm{Al}_{0.01} \mathrm{C}_{1.5} \mathrm{O}_{0.45}$ and $\mathrm{Si}_{1} \mathrm{Al}_{0.01} \mathrm{C}_{1.5} \mathrm{O}_{0.5}$ were used, respectively.

These fibers were obtained using heat-treatment of the different types of Si-Al-C-O fiber at $1900{ }^{\circ} \mathrm{C}$ in Ar using the three different types of vessels. As can be seen from this figure (Figure 5), the higher the oxygen content of Si-Al-C-O fiber becomes, the smoother the surface becomes. These results are closely related to the $\mathrm{CO}$ gas content in the reactor during the degradation reaction. The much smoother surface was obtained using the raw fiber with highest oxygen content $\left(\mathrm{Si}_{1} \mathrm{Al}_{0.01} \mathrm{C}_{1.5} \mathrm{O}_{0.5}\right)$ and the closed system. As can be seen from these results, the surface roughness is effectively controllable by changing the degradation conditions (Especially; $\mathrm{CO}$ content in the reactor). The most important factors for change in the CO content in the reactor are (1) Oxygen content of the raw Si-Al-C-O fiber, and (2) Reactor system (Open system, Partially-open system, and Closed system). By change in the combination of these factors, different degrees of the surface roughness could be effectively obtained as can be seen from Figure 5. Some phenomena caused by increase in the oxygen content of Si-Al-C-O fiber are shown as follows. As the oxygen content in the raw fiber increases, the degradation reaction becomes faster. It easily leads to nearly stoichiometric composition of the degraded fiber. In this case, the partial pressure of $\mathrm{CO}$ gas on the surface of the fiber would become higher compared with that of the other fiber with lower oxygen content. This leads to lower reaction rate at the surface of the fiber. Consequently, increase in the oxygen content of the raw Si-Al-C-O fiber led to decrease in the $\mathrm{SiC}$ crystalline size at the surface region. This means getting smooth surface. That is to say, the higher oxygen content of the raw $\mathrm{Si}-\mathrm{Al}-\mathrm{C}-\mathrm{O}$ fiber and the closed system cause relatively higher $\mathrm{CO}$ content in the reactor during the degradation reaction, and then the consequently higher partial pressure of the formed $\mathrm{CO}$ gas at the surface region reduces the reaction rate to result in getting smooth surface.

Changes in the actual surface roughness of the obtained SiC-polycrystalline fibers, which were synthesized by heat-treatment at $1900{ }^{\circ} \mathrm{C}$ in argon gas atmosphere using different raw fibers and different vessels, are shown in Figure 6. 


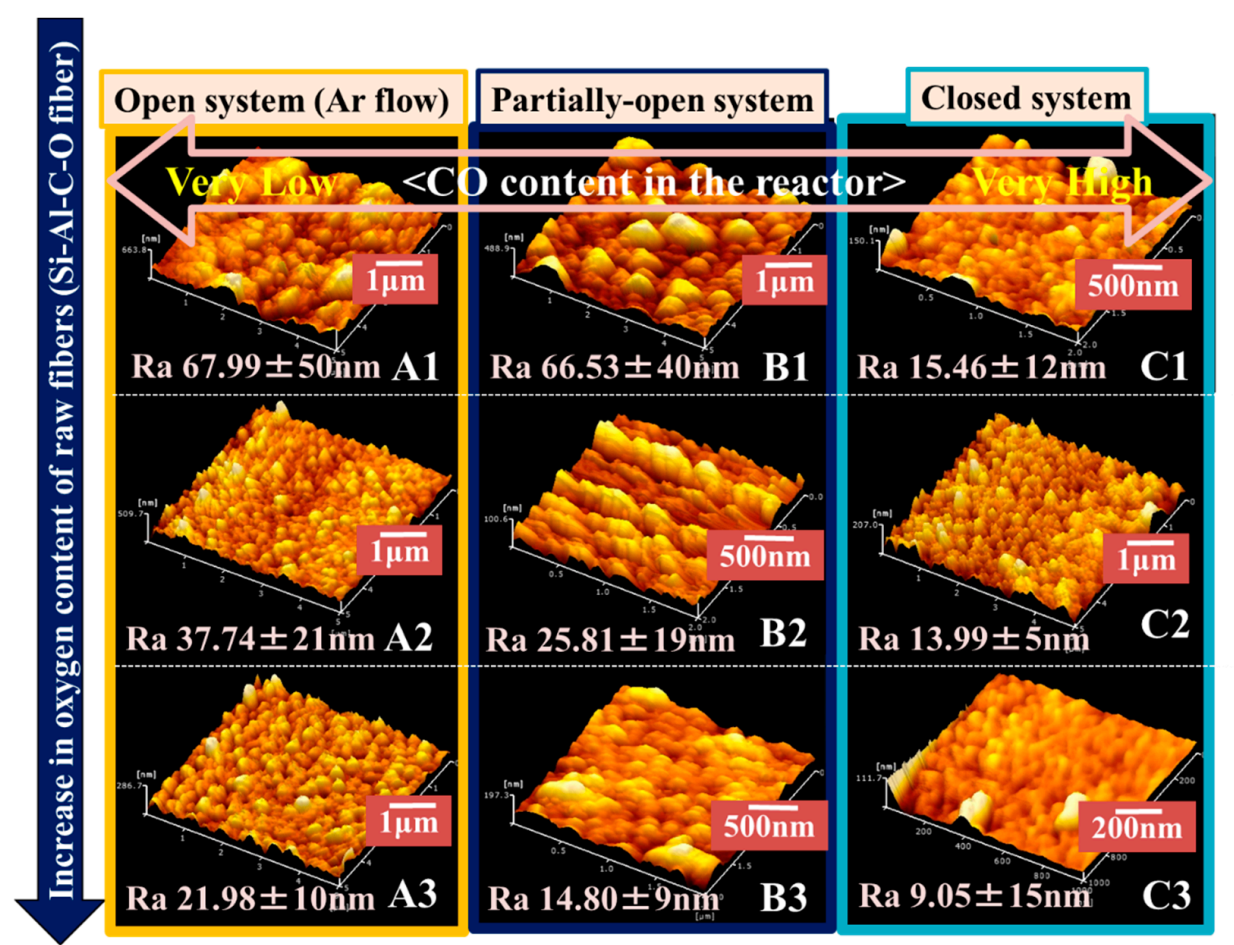

Figure 6. Change in the surface roughness of the $\mathrm{SiC}$-polycrystalline fiber synthesized from different raw Si-Al-C-O fiber with different oxygen content at $1900^{\circ} \mathrm{C}$ in argon atmosphere. For obtaining A1, B1, $\mathrm{C} 1$, the raw fiber composed of $\mathrm{Si}_{1} \mathrm{Al}_{0.01} \mathrm{C}_{1.5} \mathrm{O}_{0.4}$ was used. For obtaining $\mathrm{A} 2, \mathrm{~B} 2, \mathrm{C} 2$ and for obtaining $\mathrm{A} 3, \mathrm{~B} 3, \mathrm{C} 3$, the raw fibers composed of $\mathrm{Si}_{1} \mathrm{Al}_{0.01} \mathrm{C}_{1.5} \mathrm{O}_{0.45}$ and $\mathrm{Si}_{1} \mathrm{Al}_{0.01} \mathrm{C}_{1.5} \mathrm{O}_{0.5}$ were used, respectively.

As can be seen Figure 6, the surface smoothness could be controlled by changing both oxygen content of the raw Si-Al-C-O fiber and the reaction vessel. In this case, by the use of both the raw fiber with higher oxygen content and the closed system, that is to say, by achieving the higher oxygen content in the reactor, much smoother surface could be accomplished. As seen from Figure 6, we could control the surface roughness from $67.99 \mathrm{~nm}$ (maximum value) to $9.05 \mathrm{~nm}$ (minimum value).

As mentioned in our previous report [13], the strength of the obtained fiber is dominated by the largest defect contained in the inside of each filament. Present fibers contain relatively large defects $(100 \sim 1000 \mathrm{~nm})$. That is to say, since the strength of present fibers are dominated by the larger inside defects, the improvement of the surface smoothness from $67.99 \mathrm{~nm}$ to $9.05 \mathrm{~nm}$ could not contribute to increase in the strength. However, it would be expected to obtain the preferable property for CMCs (fiber pull-out) [17].

In this research, we used degradation process of the amorphous raw fiber (Si-Al-C-O fiber) accompanied by a release of $\mathrm{CO}$ gas and the subsequent sintering process, and also showed the controllable $\mathrm{SiC}$ crystalline size constructing the obtained $\mathrm{SiC}$-polycrystalline fiber by changing the $\mathrm{CO}$ gas partial pressure in the reactor. In consequence, we could control the surface smoothness of the SiC-polycrystalline fiber using $\mathrm{CO}$ gas released from the raw fiber. However, this means that an intentional change in $\mathrm{CO}$ gas partial pressure in the reactor can lead to preferable crystalline structure. That is to say, the obtained basic results can be applicable to the design of the industrial continuous furnace.

Finally, on the basis of our results, a perspective for developing the high-performance $\mathrm{SiC}$-polycrystalline fiber is shown in Figure 7. Our target strength will be 6GPa, which is a similar strength to that of high-performance carbon fiber (T-800). To achieve the higher strength, the most important thing is to reduce the inside defects by controlling the partial pressure of $\mathrm{CO}$ gas in the reactor during the degradation reaction of the raw amorphous fiber. Furthermore, to obtain the preferable properties for $\mathrm{CMCs}$, smoother surface must be also important. 


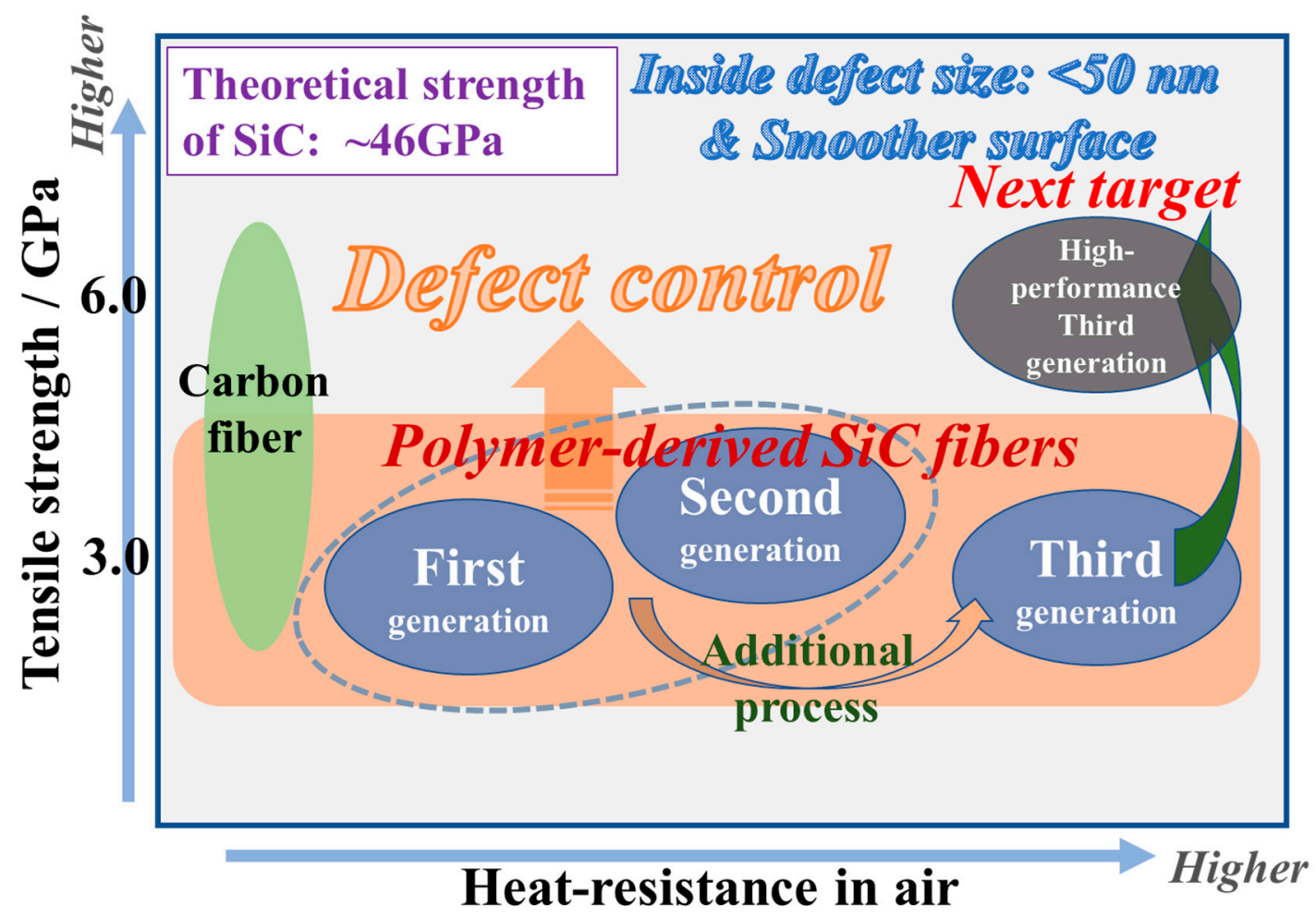

Figure 7. Perspective for the high-performance SiC-polycrystalline fiber.

\section{Conclusions}

We clarified the relationship between the heat-treatment condition and the surface smoothness of the obtained $\mathrm{SiC}$-polycrystalline fiber, using three different raw fibers (Elementary ratio: $\mathrm{Si}_{1} \mathrm{Al}_{0.01} \mathrm{C}_{1.5} \mathrm{O}_{0.4 \sim 0.5}$ ) and three different types of carbon vessels (Open system, Partially-open system, and Closed system). With increase in the oxygen content in the raw fiber (Si-Al-C-O fiber), the degradation during the heat-treatment process easily proceeded accompanied by a release of relatively high concentration of $\mathrm{CO}$ gas. When we used the raw fiber composed of $\operatorname{Si}_{1} \mathrm{Al}_{0.01} \mathrm{C}_{1.5} \mathrm{O}_{0.5}$ and closed system, much smoother surface of the obtained $\mathrm{SiC}$-polycrystalline fiber could be achieved. In this case, the degradation reactions $\left(\mathrm{SiO}+2 \mathrm{C}=\mathrm{SiC}+\mathrm{CO}\right.$ and $\left.\mathrm{SiO}_{2}+3 \mathrm{C}=\mathrm{SiC}+2 \mathrm{CO}\right)$ at the first stage in the inside of each filament became faster, and then the $\mathrm{CO}$ partial pressure at the surface region of each filament was considered to be increased. In consequence, according to Le Chatelier's principle, the surface degradation reaction and grain growth of formed $\mathrm{SiC}$ crystals would be considered to become slower.

Author Contributions: Conceptualization, T.I.; Methodology, R.U.; Software, T.I and R.U.; Formal Analysis, R.U.; Investigation, R.U.; Resources, T.I.; Writing-Original Draft Preparation, R.U.; Writing-Review \& Editing, T.I.; Supervision, T.I.

Funding: This research was funded by a Grant from NEDO (New Energy and Industrial Technology Development Organization) via Ube Industries, Ltd. We gratefully acknowledge this financial support.

Acknowledgments: The authors would like to acknowledge all support of Hiroshi Oda and Hiroyuki Yamaoka of Ube Industries, Ltd.

Conflicts of Interest: The authors declare no conflict of interest. The funder had no role in the design of the study; in the writing of the manuscript, and in the decision to publish the results. 


\section{References}

1. Yajima, S.; Okamura, K.; Hayashi, J.; Omori, M. Synthesis of Continuous SiC Fibers with High Tensile Strength. J. Am. Ceram. Soc. 1976, 59, 324-327. [CrossRef]

2. Flores, O.; Bordia, R.K.; Nestler, D.; Krenkel, W.; Motz, G. Ceramic Fibers Based of SiC and SiCN Systems: Current Research, Development, and Commercial Status. Adv. Eng. Mater. 2014, 16, 621-636. [CrossRef]

3. Lipowitz, J.; Barnard, T.; Bujalski, D.; Rabe, J.; Zank, G. Fine-diameter Polycrystalline SiC Fibers. Compos. Sci. Technol. 1994, 51, 167-171. [CrossRef]

4. Su, Z.; Zhang, L.; Li, Y.; Li, S.; Chen, L. Rapid Preparation of SiC Fibers Using a Curing Rought of Electron Irradiation in a Low Oxygen Concentration Atmosphere. J. Am. Ceram. Soc. 2015, 98, 2014-2017. [CrossRef]

5. Ishikawa, T.; Kohtoku, Y.; Kumagawa, K.; Yamamura, T.; Nagasawa, T. High-strength alkali-resistant sintered $\mathrm{SiC}$ fibre stable to $2200{ }^{\circ} \mathrm{C}$. Nature 1998, 391, 773-775. [CrossRef]

6. Takeda, M.; Urano, A.; Sakamoto, J.; Imai, Y. Microstructure and oxidative degradation behavior of silicon carbide fiber Hi-Nicalon type S. J. Nuclear Mater. 1998, 258, 1594-1599. [CrossRef]

7. Ishikawa, T. Advances in Inorganic Fibers. In Advanced Polymer Science; Springer: Berlin, Germany, 2005; Volume 178, pp. 109-144.

8. Sha, J.J.; Nozawa, T.; Park, J.S.; Katoh, Y.; Kohyama, A. Effect of heat treatment on the tensile strength and creep resistance of advanced SiC fibers. J. Nuclear Mater. 2004, 329, 592-596. [CrossRef]

9. Itatani, K.; Hattori, K.; Harima, D.; Aizawa, M.; Okada, I. Mechanical and thermal properties of silicon-carbide composites fabricated with short Tyranno Si-Zr-C-O fiber. J. Mater. Sci. 2001, 36, 3679-3686. [CrossRef]

10. Gosset, D.; Colin, C.; Jankowiak, A.; Vandenberghe, T.; Lochet, N. X-ray Diffraction Study of the Effect of High-Temperature Heat Treatment on the Microstructural Stability of Third-Generation SiC Fibers. J. Am. Ceram. Soc. 2013, 96859, 1622-1628. [CrossRef]

11. Kondo, S.; Hinoki, T.; Nonaka, M.; Ozawa, K. Irradiation-induced shrinkage of highly crystalline SiC fibers. Acta Mater. 2015, 83, 1-9. [CrossRef]

12. Oda, H.; Ishikawa, T. Microstructure and mechanical properties of SiC-polycrystalline fiber and new defect-controlling process. Int. J. Appl. Ceram. Technol. 2017, 14, 1031-1040. [CrossRef]

13. Ishikawa, T.; Oda, H. Defect control of $\mathrm{SiC}$ polycrystalline fiber synthesized from poly-aluminocarbosilane. J. Eur. Ceram. Soc. 2016, 35, 3657-3662. [CrossRef]

14. Ishikawa, T.; Oda, H. Structural control aiming for high-performance SiC polycrystalline fiber. J. Korean Ceram. Soc. 2016, 53, 615-621. [CrossRef]

15. Usukawa, R.; Oda, H.; Ishikawa, T. Conversion process of amorphous Si-Al-C-O fiber into nearly stoichiometric $\mathrm{SiC}$ polycrystalline fiber. J. Korean Ceram. Soc. 2016, 53, 610-614. [CrossRef]

16. Zhao, X.; Langford, R.M.; Shapiro, I.P.; Xiao, P. Onset plastic deformation and cracking behavior of silicon carbide under contact load at room temperature. J. Korean Ceram. Soc. 2011, 94, 3509-3514. [CrossRef]

17. Sauder, C.; Brusson, A.; Lamon, J. Influence of interface characteristics on the mechanical properties of Hi-Nicalon type-S or Tyranno-SA3 fiber-reinforced SiC/SiC minicomposites. Int. J. Appl. Ceram. Technol. 2010, 7, 291-303. [CrossRef]

(C) 2018 by the authors. Licensee MDPI, Basel, Switzerland. This article is an open access article distributed under the terms and conditions of the Creative Commons Attribution (CC BY) license (http://creativecommons.org/licenses/by/4.0/). 